\title{
Health knowledge, attitudes and practices of family planning service providers and clients in Akwapim North District of Ghana
}

\author{
Margaret Duah Atuahene ${ }^{1 *}$, Esther Oku Afari ${ }^{2}$, Martin Adjuik ${ }^{3}$ and Samuel Obed ${ }^{4}$
}

\begin{abstract}
Background: Family planning services help save lives by reducing women's exposure to risks of child birth and abortion. While family planning services provide measures to prevent unintended pregnancies and time the formation of families, the acceptability and coverage is still very low worldwide. Some of the reasons for this include poor quality of service, unavailability of range of methods, fear of opposition from partners, side effects and health concerns among others.

About $40 \%$ of the world's 215,000 annual deaths in childbirth occur in the Sub-Saharan region. In Ghana, urban-rural fertility differences range from two to three children. The acceptability and coverage of family planning are still low and in the study area in particular.

Methods: We sought to examine factors that contribute to low acceptability and coverage of family planning services in a sub-urban community with a design of quantitative cross-sectional. Ethical approval was given by the Ghana Health Service. Midwives and community health nurses who provide family planning services were interviewed. Exit-interview was also conducted with women receiving a variety of outpatient services.
\end{abstract}

Results: Most of the women in this study (48.7 \%) were in the 25-34 age range and were either married (42.8 \%) or cohabiting (40.5\%). Majority of these women (67.7\%) have middle/Junior high level of formal education with a modal parity of two. Sixty eight (68) clients were identified as current family planning users. About $6.0 \%$ and $4.5 \%$ were dissatisfied about auditory and visual privacy during counselling respectively. This was confirmed by providers who attributed it to inappropriate facility layout. Most of the clients (79.1\%) were not given educational materials although $88.8 \%$ were talked to about family planning and this could be due to unavailability of these hand-outs.

Though clients show satisfaction of services received, providers did not follow standard protocols with as much as $73.7 \%$ faced with challenges in provision of services which were attributed to improper facility layout and lack of furniture. About $77.2 \%$ were willing to provide short term methods, while $91.2 \%$ wanted to provide long term methods. As much as $93.3 \%$ of the women said they would have liked providers give more detailed information on family planning. While most of the women ( $88.3 \%$ ) used injectables, only $6.1 \%$ and $0.9 \%$ used Implants and IUD respectively.

Conclusions: Finding ways to improve client privacy through good facility layout will ensure visual and auditory privacy to enhance family planning service provision and uptake. Continuous competency training will assist providers design innovative action plans and meet client satisfaction needs.

Keywords: Reproductive Health, Family Planning, Sub-Saharan Africa, Provider, Contraceptive, Client, Survey, Service provision

\footnotetext{
* Correspondence: matuahene@ug.edu.gh

${ }^{1}$ School of Public Health, University of Ghana, Accra, Ghana

Full list of author information is available at the end of the article
} 


\section{Background}

\section{Unintended pregnancy}

About 80 million unintended pregnancies are estimated to occur worldwide annually and in developing countries more than one-third of all pregnancies are considered unintended and about $19 \%$ will end up in abortion, which are most often unsafe accounting for $13 \%$ of all maternal deaths globally $[1,2]$. Two-thirds of unintended pregnancies in developing countries occur among women who are not using any method of contraception. This indicates the failure to take necessary decisions to prevent and avoid unwanted pregnancies [3].

Globally, 50 million women resort to induced abortion which ultimately results in high maternal morbidity and mortality. In 2007, an estimated 536,000 maternal deaths occurred globally with $1 \%$ in developed countries and $50 \%$ in Sub-Saharan Africa [4].

\section{Contraceptive uptake}

Contraceptive uptake is low in rural areas and lag behind urban populations [5]. In Ghana, urban-rural fertility differences range from two to three [6]. The poorest rural wealth quintiles have modern contraceptive levels ranging from less than $5 \%$ to about $15 \%$ of eligible women [7]. Current evidence shows slow progress in expanding the use of contraceptives by women of low socioeconomic status [8].

Access to contraceptives can also be inhibited by certain provider practices such as use of excessively restrictive medical criteria or provider bias against certain methods; these practices are often referred to as medical barriers. Therefore, identifying and addressing these barriers may facilitate improvements in quality of care and subsequently uptake of family planning services. While quality of family planning services may be good, clients report barriers such as misinformation and provider disrespect [9]. In other words, lack of education materials or being misinformed, and showing no dignity for clients were considered as barriers to accessing family planning and other health delivery services.

\section{Benefits of family planning}

Family planning can reduce the number of deaths among women by reducing the number of women who are at risk by averting unintended pregnancy, which accounts for about $30 \%$ of all births in Sub-Saharan Africa [10]. Therefore, family planning can reduce maternal mortality though access to quality of service is a major concern [11]. Other benefits of family planning include prevention of cancers and sexually transmitted diseases [12].

The benefits are well established [13, 14]. In some African countries, about one-third of women's need for family planning is unmet, such as Rwanda with $38 \%$ and Uganda with $41 \%$. Encouragingly, an analysis of survey data showed a significant level of women with unmet need who had never used family planning intended to do so [15].

\section{Birth spacing}

The growing use of contraception around the world has given couples the ability to choose the number and spacing of their children which have tremendous lifesaving benefits. Yet despite these impressive gains, contraceptive use is still low and the need for contraception high in some of the world poorest and most populous places [16]. In the past 20 years alone, maternal deaths in developing countries have been reduced by $40 \%$ [17]. Family planning programmes have been effective in the past and have played a major part in increasing the use of contraception from 10 to $60 \%$ and reducing average fertility in developing countries from 6 to 3 births per woman [18].

\section{Unmet needs}

Fertility rates in sub-Saharan Africa remain high and more than twice the global average [19-21]. Women who prefer spacing births but are not using contraception are considered to have unmet need [22]. While access also to affordable modern methods of contraception is sometimes a problem, many women reported other reasons for not using family planning, such as not perceiving themselves at risk of pregnancy because they did not have sex frequently, were going through menopause or were lactating. But these situations do not offer protection against pregnancy in all cases [23].

\section{Accessibility}

Women living in urban areas may have greater access to a wide variety of contraceptive services and methods as compared to rural women [24]. In this light, it is obvious that the poor cannot access family planning counselling and other services, due to high cost and proximity accounting for unmet needs and low family planning coverage.

Facilitating access to modern contraceptives for women with unmet needs has the potential benefit of improving maternal child health and reducing mortalities [12, 25-28].

This study was to assess knowledge, attitude, perceptions and practices of providers, whilst attempting to understand the perspectives, needs and motivations of clients that may help address barriers to uptake and adherence to family planning standard and procedures.

\section{Methods}

A cross-sectional quantitative descriptive study was designed to collect information on knowledge, attitude and practices in provision of family planning services among women of reproductive age and service providers in the Akwapim North District. The district has an estimated population of 122,063 and $3.1 \%$ growth 
rate. There are two hospitals, seven health centres and sixteen Community Health Planning Services (CHPS) compounds. There is an estimated 28,075 women in the fertility age, with family planning coverage of roughly $27 \%$.

\section{Sampling of study participants}

The sample size for the study was computed as follows: The population proportion formula: $\mathrm{n}=\mathrm{z}^{2 *} \mathrm{p} *(1-\mathrm{p}) / \mathrm{d}^{2}$, was applied, where $\mathrm{n}$ is the desired sample size, $\mathrm{z}$ is the standard normal deviate at the $95 \%$ confidence level, $\mathrm{p}$ is the proportion of women who assessed family planning services in the study area and $d$ is degree of accuracy desired; and. Thus using $\mathrm{z}=1.96, p=0.27$, and $\mathrm{d}=0.05$, the calculated sample size for clients (women in reproductive age) was 303.

From the district records, 7,580 clients were active family planning users in 2012. Therefore, applying the finite population correction factor, where $\mathrm{n} 1$ is the required sample size; and $\mathrm{N}$ is the population of clients who utilizes family planning services; a final sample size of 291 was estimated. The study population comprised women of reproductive age (15-49 years) who sought family planning services regardless of their reproductive status and they have to be residents in the district.

\section{Study population}

The study population for this research is defined as women of reproductive age (15-49 years) resident in the district who receive family planning services and providers who offer family planning services made up of mostly midwives and nurses. They included current family planning users and other women seeking ANC, post-partum and STI services. Also forming part of the study population were midwives and community health nurses who are providers of family planning services. Family planning services are accessed in these comprehensive clinics that provide family planning as part of inclusive health delivery. As a result of cultural stigmatization associated with family planning accessibility, most women prefer seeking services in clinics where FP services are provided alongside with other services. This is deliberately arranged to prevent being stigmatized for only family planning. In other words, it is shrouded in secrecy. In this study sixty eight (68) clients were identified as current family planning users as indicated in Tables 2 and 3.

All midwives and community health nurses in the study area were interviewed for information on access and utilization of family planning services among women of reproductive age. Exit-interviews were conducted with women attending family planning clinic and ante-natal care (ANC). A combined checklist and structured questionnaire were used to collect information from service providers while structured questionnaire were administered to clients.
Clients responded in English and local dialects for those who required translation. Information was kept confidential and names of participants were not included in the analysis or reported in the study results.

\section{Quality control}

Data were checked for completeness and accuracy. Regular verification and validation of data were done with all inconsistencies being checked and resolved with the research assistants and data entry clerks. The data were entered using EPIDATA 3.1 software and imported to statistical software, STATA version 11.

To ensure quality and validity of data, the following measures were put in place. Research assistants with requisite background were recruited and trained on data collection guidelines. The survey was administered by the authors and assisted by trained research assistants. Collected data were checked to ensure that all questions were answered. Probing was done where necessary during interviewing.

Errors detected were discussed and necessary corrections made. Every questionnaire was marked to prevent double entry. Financial constraints - funds were not readily available. Access to some parts of study area was very difficult due to the poor nature roads. Some measures were taken which included researchers being objective in dealing with respondents, financing of the study was from researchers' own resources and managed to get to catchments areas by their own means of transport.

\section{Ethical review}

Ethical clearance was obtained from the Ghana Health Service's Ethical Review Committee and permission was sought from the District Health Administration. All participants were assured of anonymity and confidentiality and participation was voluntary. They were assured that the results will purely be used for research purposes.

\section{Results \\ Background characteristics of family planning clients}

The majority of family planning clients in the exitinterview (48.7\%) were aged 25-34 years, $30.1 \%$ were aged $15-24$ years, and $19.0 \%$ were aged $35-44$ years (Table 1). Out of the total (269), $42.8 \%$ were married and $40.5 \%$ cohabited. The remaining $16.7 \%$ were either single, or never married. $67.7 \%$ of the women had Middle/Junior High level of education and $24.9 \%$ and $20.8 \%$ had parity of two and four respectively. The modal number of children alive was two children (26.0 \%) followed by one child (21.9\%). 
Table 1 Basic Demographic characteristics of Family Planning Clients $(N=269)$

\begin{tabular}{|c|c|c|}
\hline Variables & Number (n) & Proportion (\%) \\
\hline \multicolumn{3}{|l|}{ Age Group } \\
\hline $15-24$ & 81 & 30.1 \\
\hline $25-34$ & 131 & 48.7 \\
\hline $35-44$ & 51 & 19.0 \\
\hline $45+$ & 6 & 2.2 \\
\hline \multicolumn{3}{|l|}{ Marital status } \\
\hline Married & 115 & 42.8 \\
\hline Cohabiting & 109 & 40.5 \\
\hline Single, Never married & 45 & 16.7 \\
\hline \multicolumn{3}{|l|}{ Level of Education } \\
\hline None & 4 & 1.5 \\
\hline Primary & 50 & 18.6 \\
\hline Middle/Junior High & 182 & 67.7 \\
\hline Secondary & 33 & 12.3 \\
\hline \multicolumn{3}{|l|}{ Parity } \\
\hline Parity 0 & 43 & 16.0 \\
\hline Parity 1 & 55 & 20.5 \\
\hline Parity 2 & 67 & 24.9 \\
\hline Parity 3 & 48 & 17.8 \\
\hline Parity 4 & 56 & 20.8 \\
\hline \multicolumn{3}{|l|}{ Number of children alive } \\
\hline None & 30 & 11.2 \\
\hline One & 59 & 21.9 \\
\hline Two & 70 & 26.0 \\
\hline Three & 51 & 19.0 \\
\hline Four & 37 & 13.8 \\
\hline Five & 22 & 8.2 \\
\hline
\end{tabular}

Source: Fieldwork, June 2014
Table 2 Current Family Planning Clients' Assessment of Provider Knowledge and Skills ( $N=68)$

\begin{tabular}{|c|c|c|}
\hline Variables & Number(n) & Proportion (\%) \\
\hline \multicolumn{3}{|c|}{ Asked about children in the future } \\
\hline Yes & 51 & 75.1 \\
\hline No & 16 & 23 \\
\hline Don't know & 1 & 1.9 \\
\hline \multicolumn{3}{|c|}{ Received FP Material } \\
\hline Yes & 14 & 20.8 \\
\hline No & 54 & 79.2 \\
\hline \multicolumn{3}{|c|}{ Talked to about FP } \\
\hline Yes & 60 & 88.9 \\
\hline No & 8 & 11.1 \\
\hline \multicolumn{3}{|c|}{ Would have liked hand-outs about FP } \\
\hline Yes & 63 & 93.3 \\
\hline No & 5 & 6.7 \\
\hline \multicolumn{3}{|c|}{ Method using currently } \\
\hline Oral pills & 3 & 4.8 \\
\hline Injectable & 60 & 88.2 \\
\hline Implants & 4 & 6.1 \\
\hline IUD & 1 & 0.9 \\
\hline \multicolumn{3}{|c|}{ Provider discussed new method } \\
\hline Yes & 18 & 26.4 \\
\hline No & 50 & 73.6 \\
\hline \multicolumn{3}{|c|}{ Waiting time for FP } \\
\hline Too long & 1 & 1.7 \\
\hline Reasonable & 67 & 98.3 \\
\hline \multicolumn{3}{|c|}{ You will recommend the facility to a friend } \\
\hline Yes & 64 & 94.4 \\
\hline No & 4 & 5.6 \\
\hline
\end{tabular}

Source: Fieldwork, June 2014

may not have been exposed to family planning before their visits to the clinics. Still, some could have been first time mothers, with unplanned pregnancies who may not have used family planning at all in their lives but desired to do so shortly or in the future. All participants were exposed to family planning information before they exited the clinics or health centres. While most (88.2\%) used injectables, only $6.1 \%$ and $0.9 \%$ used Implants and IUD, respectively. A large proportion $(98.3 \%)$ said the waiting time was reasonable and $94.4 \%$ said they would recommend the facility to a friend for family planning services.

Level of satisfaction of FP services by current FP clients All current family planning clients said they were satisfied with discussions on problems and concerns, explanation given, quality of examination, visual and auditory users. Some of the women were ante-natal patients and 
privacy, cleanliness and interaction with facility staff as indicated in Table 3.

Characteristics of FP facilities and service providers $(N=70)$ Table 4 shows the basic characteristics of family planning facilities and service providers. The number of FP providers interviewed was 70 . A proportion of $82.1 \%$ were females, $78.9 \%$ constituted Community Health Nurses $(\mathrm{CHN})$ and $49.1 \%$ had been in their current position for up to 2 years. Their mean age was 31.5 years with a standard deviation of 9.8 years.

\section{FP service provision from provider perspective}

Table 5 indicates family planning service provision from the perspective of the provider. Most (75.4 \%) said they receive their supplies monthly. About $77.2 \%$ provided information, counselling, short term method and with $91.2 \%$ interested in long term methods. As much as $73.7 \%$ indicated facing challenges including improper facility layout and lack of furniture.

\section{Discussions}

\section{Socio-demographic profile}

Most of the women (48.7\%) aged 25-34 and were either married (42.8\%) or cohabiting (40.5\%). This means that most of the women are in active reproductive age and in active nuptial union. Majority of these women also have more middle/Junior high level of schooling with a parity of two. This revealed that, those who had received some level of formal education are in the majority, compared to those without any form of education. Studies have shown that, further educational and class differences between clients and providers often limit clients' ability to access services [29].

\section{Confidentiality and privacy}

The desire to have more children supports a study done in the region of Tigray which showed that African men

Table 3 Level of satisfaction of FP services by current FP clients

\begin{tabular}{llll}
\hline Areas of satisfaction of services & \multicolumn{3}{l}{ Level of satisfaction of FP services } \\
\cline { 2 - 4 } & Satisfied & Dissatisfied & Undecided \\
\hline $\begin{array}{l}\text { Discussion of concerns with } \\
\text { provider }\end{array}$ & $68(100)$ & $0(0)$ & $0(0)$ \\
$\begin{array}{l}\text { Explanation provided about } \\
\text { problem }\end{array}$ & $68(100)$ & $0(0)$ & $0(0)$ \\
$\begin{array}{l}\text { Quality of examination provided } \\
\text { by provider }\end{array}$ & $62(91.8)$ & $5(7.4)$ & $1(0.8)$ \\
$\begin{array}{l}\text { Visual privacy during examination } \\
\text { Auditory privacy during discussion }\end{array}$ & $65(95.2)$ & $3(4.8)$ & $0(0)$ \\
Cleanliness of the facility & $68(100)$ & $4(6.3)$ & $0(0)$ \\
$\begin{array}{l}\text { Treatment received from } \\
\text { facility staff }\end{array}$ & $68(100)$ & $0(0)$ & $0(0)$ \\
\hline
\end{tabular}

Source: Fieldwork, June 2014
Table 4 Characteristics of FP facilities and service providers $(N=70)$

\begin{tabular}{llc}
\hline Characteristics & Number(n) & Proportion (\%) \\
\hline Type of facility & 5 & 7.1 \\
Hospital & 25 & 35.7 \\
Health Centre & 30 & 42.9 \\
CHPS Compound & 10 & 14.3 \\
Others & & \\
Gender of service provider & 13 & 17.9 \\
Male & 57 & 82.1 \\
Female & & \\
Professional qualification & 7 & 10.5 \\
Midwife & 1 & 1.8 \\
SRN & 55 & 78.9 \\
CHN & 3 & 3.5 \\
Enrolled Nurse & 1 & 1.8 \\
HCA & 3 & 3.5 \\
Others & & \\
Length of service & 15 & 21.1 \\
$<1$ year & 34 & 49.1 \\
1-2 years & 21 & 29.8 \\
$3+$ years & $31.5 \pm 9.8$ & \\
Age in years (mean \pm SD) & & \\
\hline
\end{tabular}

Source: Fieldwork, June 2014

generally, desire more children because of social and economic benefits. Studies have shown that clients, particularly those who obtain services in secret, report higher satisfaction with providers who keep their needs and personal information confidential [30]. Therefore, lack of privacy can violate women's sense of modesty and make it more difficult to participate actively in family planning services.

Though clients generally indicate satisfaction about counselling, quality of examination, cleanliness of facility and treatment, some $6.0 \%$ and $4.5 \%$ were dissatisfied about auditory and visual privacy respectively. In a similar study in Zambia, clients based their judgment on how thoroughly they were examined due to confidentiality and privacy [31]. In Chile, all but one respondent mentioned the facility's cleanliness as a sign of the quality of the clinic's services [32].

\section{Cultural perspective and family planning services}

It was also revealed [33] that in a few places, obtaining and using contraceptives can be a difficult and risky decision that can lead to abandonment, violence, ostracism, or divorce hence women need assurance of absolute confidentiality. This result is similar to a recent research in which clients' perspectives on services they receive are essential part of understanding and assessing quality of care [34]. Other studies have shown that, clients' perceptions 
Table 5 FP Service Provision from Provider Perspective

\begin{tabular}{|c|c|c|}
\hline Variables & $\begin{array}{l}\text { Number } \\
\text { (n) }\end{array}$ & $\begin{array}{l}\text { Proportion } \\
(\%)\end{array}$ \\
\hline \multicolumn{3}{|c|}{ Frequency of FP supply } \\
\hline Weekly & 1 & 1.8 \\
\hline Monthly & 53 & 75.4 \\
\hline Quarterly & 15 & 21.1 \\
\hline Others & 1 & 1.8 \\
\hline \multicolumn{3}{|c|}{$\begin{array}{l}\text { FP Services willing to Provide FP } \\
\text { information }\end{array}$} \\
\hline Yes & 54 & 77.2 \\
\hline No & 16 & 22.8 \\
\hline \multicolumn{3}{|c|}{ FP Counselling } \\
\hline Yes & 54 & 77.2 \\
\hline No & 16 & 22.8 \\
\hline \multicolumn{3}{|c|}{ FP Short Term methods } \\
\hline Yes & 54 & 77.2 \\
\hline No & 16 & 22.8 \\
\hline \multicolumn{3}{|c|}{ FP Long term methods } \\
\hline Yes & 64 & 91.2 \\
\hline No & 6 & 8.8 \\
\hline \multicolumn{3}{|c|}{$\begin{array}{l}\text { Faced with challenges in FP services } \\
\text { provision }\end{array}$} \\
\hline Yes & 52 & 73.7 \\
\hline No & 18 & 26.3 \\
\hline
\end{tabular}

Source: Fieldwork, June 2014

are shaped by their cultural values, previous experiences, perceptions of the role of the health system and interactions with providers. Their perceptions affect how clients view the risks and benefits of care [35].

Again, studies have shown that clients may also indicate that they are satisfied with care because they want to please the interviewer, worry that care may be withheld in the future, or have some cultural or other reason to fear complaining [36]. Many clients have limited options and have never experienced any other standards of care.

\section{Provider and client relationship}

The results show that, the providers were able to build a good rapport with their clients by greeting and introducing themselves. This finding contradicts that in a study by [9] where providers failed to greet clients in a respectful or friendly manner and generally displayed negative attitudes towards clients. In many societies, courtesy is a sign that the client is regarded as the provider's equal. Research shows that the provider's tone, manner, and modes of speech are important to clients [37-39].
Studies found that women are more likely to seek out and continue using family planning services if they receive respectful and friendly treatment [11,32, 40], as cited in $[33,41]$. A good proportion of the clients $(38.6 \%$ and $32.9 \%)$ were not asked about previous pregnancy/reproductive and family planning history respectively.

\section{Information and educational materials}

Results from the checklist shows that greater proportions (61.4\%) of them were not provided with educational hand-outs. This confirms the result from the client exit interview where most (79.2 \%) of the clients said they were not given family planning materials. Some $22.8 \%$ were not willing to provide FP counselling and short term methods though most $(88.3 \%)$ of the clients are on injectables (short-term). About $26.3 \%$ of the providers said they face challenges in the provision of services and majority (91.2 \%) prescribed long term methods. Research has shown that providing more complete and accurate counselling that is tailored to the client's needs, including providing hand-outs has been associated with higher levels of client satisfaction, as well as higher contraceptive prevalence and client retention [36].

\section{Limitation of the study}

This study is not without limitations. The sensitive nature of some questions may have resulted in some bias. Thus there could be the possibility of reporting behaviours that are socially desirable. Subjectivity which could have resulted in bias, in an effort to relegate our values and beliefs to the background, when dealing with respondents. However, the purpose of the study was explained to the best of our ability. This was done to prepare participants to provide objective views to help improve family planning services in the community.

\section{Conclusions and recommendations}

Although family planning clients show a general satisfaction about the provision of family planning services, it was clear that providers were not following the standard or protocols when attending to clients. These depend on the counselling skills, adherence to principles in phases and steps during encounter with clients.

Family planning clients in study area do not identify any negative attitude of service providers that hinder access to family planning services but were concerned about their visual and auditory privacy. This was again confirmed by service providers who said the facility layout is a challenge in service provision. Identifying the problems, retraining providers, and using clear protocols for engaging clients resulted in much improved clientprovider interactions and addressed the needs of clients, providers, and program managers. 
Finding ways to enhance client privacy through good facility layout for visual and auditory privacy, increase provider skills and expertise to ensure all phases and steps in family planning counselling (rapport building, exploration, decision making and implementing the decision) are followed. This could be done through good supervision and refresher courses. Training is especially needed to equip providers offer short and long term services to enhance and scale up family planning services in communities.

\section{Abbreviations}

WHO: World Health Organization; UNFPA: United Nation's Fund for Population Activities; CYP: Couple year protection; FP: Family planning; CHPS: Community Health Planning Services; TF: Total fertility rate; CHN: Community health nurses SRN, senior registered nurse; SRN: senior registered nurse; HCA: Health Care Administrator; IEC: Information, education, and communication.

\section{Competing interest}

The authors declare that they have no competing interests.

\section{Authors' contributions}

MDA and EOA conceived the study and worked on the research proposal. EOA led the field work. MA, MDA and EOA performed statistical analysis and contributed to the interpretation of data. MDA worked on the first portion and the final writing of the manuscript with MA and SO. All authors were involved in the revision of the manuscript and have approved it for publication.

\section{Acknowledgement}

We are grateful and acknowledge the support of Professor Moses Aikins, Dr Abu Manu, the District Director of Health Services, staff and clients for their contribution. Our gratitude goes to the entire community for the immense assistance in diverse ways up to the conclusion of this project.

\section{Author details}

${ }^{1}$ School of Public Health, University of Ghana, Accra, Ghana. ${ }^{2}$ Ministry of Health, Akwapim, Ghana. ${ }^{3}$ INDEPTH Network Secretariat, Accra, Ghana.

${ }^{4}$ Korle-Bu Teaching Hospital, Accra, Ghana.

Received: 14 June 2015 Accepted: 26 February 2016

Published online: 07 March 2016

\section{References}

1. Guttmacher Institute. The role of reproductive health providers in preventing HIV, Issues in brief. 2004

2. Marston C, Cleland J. Relationships between contraception and abortion: a review of the evidence. Int Fam Plan Perspect. 2003;29:6-13.

3. Malwenna LI, Jayawardana PL, Balasuriya A. Effectiveness of a community based health educational intervention in reducing unmet need for modern methods of family planning among ever married reproductive age women in the Kalutara District Siri Lanka. Int J Collabarative Res Intern Med Public Health. 2012:4:1097-114.

4. WHO. Reducing risk, promoting healthy life. Who report, statistical annex. Geneva: WHO; 2002

5. WHO/UNFPA/UNICEF 1995. Study Group on Programming for Adolescent Health: Programming for Adolescent Health. (Discussion Paper). www. Pathfinder.org

6. Ghana Demographic and Health Survey. Ghana Statistical Service, Ghana Health Service Accra, Ghana; 2008.

7. Futures Group. International Planned Parenthood Federation. 2010. www. advancefamilyplanning.org/futures-group.

8. Boerma JT, Bryce J, Kinfu Y, Axelson H, Victora CG. Mind the gap: equity and trends in coverage of maternal, newborn, and child health services in 54 Countdown countries. Lancet. 2008;371(9620):1259-67.
9. Tumlinson K, Speizer IS, Archer LH, Behets F. Simulated clients reveal factors that may limit contraceptive use in Kisumu, Kenya. Glob Health Sci Pract. 2013;1:407-16.

10. WHO. Annual report. 2010.

11. Miller R, Ndhlovu L, Gachara M, Fisher A. The situation analysis study of the family planning program in Kenya. Stud Fam Plann. 1992:22:131-43.

12. Cleland J, Bernstein S, Ezeh A, Faundes A, Glasier A, Innis J. Family planning: the unfinished agenda. Lancet. 2006;368:1810-27.

13. Cohen S. Promoting sexual and reproductive health advances maternal health. Guttmacher Policy Rev. 2009;12(2):8-12.

14. Hogan F, Naghavi A, Wang M. Maternal mortality for 181 countries, 1980-2008: a systematic analysis of progress towards millennium development goal 5. Lancet. 2010:375:1609-23.

15. Westoff C. Unmet need at the end of the century. Calverton: ORC Macro; 2001 (DHS Comparative Reports No. 1).

16. Smith R, Ashford L, Gribble J, Clifton D. Population Reference Bureau (PRB) Family Planning Saves Lives. 4th Ed. Washington, DC; 2009.

17. Cleland J, Conde-Agudelo A, Peterson H, Ross J, Tsui A. Contraception and health. Lancet. 2012;380:149-56.

18. Cleland J, Bernstein S, Ezeh A, Faundes A, Glasier A, Innis J. Family planning: the unfinished agenda. 2006

19. The Population Reference Bureau (PRB). (2009). Family planning saves lives 4th ed. Washington, DC

20. Population Reference Bureau (PTB) (2012a). Datafinder. Washington, DC.

21. Population Reference Bureau (2012b). Datafinder: Africa-Sub- Saharan. Washington, DC

22. Measure DHS. Unmet need for family planning. Calverton: ICF International; 2012

23. Ashford L. Unmet need for family planning: recent trends and their implications for programs. Washington, DC: Population Reference Bureau; 2003

24. Hong R, Montana L, Mishra V. Family planning services quality as a determinant of use of IUD in Egypt. BMC Health Serv Res. 2006;6:79.

25. Benagiano G, Bastianelli C, Farris M. Contraception: a social revolution. Eur J Contracept Reprod Health Care. 2007;12(1):3-12

26. Conde-Agudelo A, Belizan JM. Maternal morbidity and mortality associated with interpregnancy interval: cross sectional study. BMJ. 2000;321(7271):1255-9.

27. Zhu BP, Rolfs RT, Nangle BE, Horan JM. Effect of the interval between pregnancies on perinatal outcomes. N Engl J Med. 1993;340(8):589-94.

28. Rutstein SO. Effects of preceding birth intervals on neonatal, infant and under-five years mortality and nutritional status in developing countries: evidence from the demographic and health surveys. Int J Gynaecol Obstet. 2005;89 Suppl 1:S7-S24.

29. Creel LZ, Sass JV, Yinger NV. Client-centered quality: clients' perspectives and barriers to receiving care population reference bureau. 2002.

30. Whittaker M, Mita R, Hossain B, Koenig M. Evaluating rural Bangladeshi women's perspectives of quality in family planning services. Health Care Women Int. 1996;17(5):393-411.

31. Ndulo J. Quality of care in sexually transmitted diseases in Zambia: patients' perspectives. East Afr Med J. 1995;72(10):641-44

32. Hernán V. The client's view of high-quality care in Santiago, Chile. Stud Fam Plann. 1993;24(1):40-9.

33. Williams TW. Measuring family planning service quality through client satisfaction exit interviews. Int Fam Plan Perspect. 2000;26(2):63-71.

34. Kelley E, Boucar M. Helping district teams measure and act on client satisfaction data in Niger, Operations research results 1, no. 1. Bethesda: U.S. Agency for International Development, Quality Assurance Project; 2000.

35. Kols AJ, Sherman JE. Family planning programs: improving quality, Population reports 26, no. 3. Baltimore: Johns Hopkins University School of Public Health, Population Information Program; 1998.

36. Whittaker A. Quality of care for women in Northeast Thailand: intersections of class, gender, and ethnicity. Health Care Women Int. 1996;17(5):435-47.

37. Schuler SR, Hossain Z. Family planning clinics through women's eyes and voices: a case study from rural Bangladesh. Int Fam Plan Perspect. 1998:24(4):170-75.

38. Matamala MI. Gender-related indicators for the evaluation of quality of care in reproductive health services. Reprod Health Matters. 1998:6(11):10-21.

39. Kenny DT. Determinants of patient satisfaction with the medical consultation. Psychol Health. 1995;10(5):427-37. Quoted in Barbara Barnett and Jane Stein, Women's Voices, Women's Lives: The Impact of Family Planning (Research Triangle Park, NC. Women's Studies Project, Family Health International 1998) 
40. Stein $K$, Measham D, Winikoff $B$. The quality of family planning services for breastfeeding women in Senegal. Int Fam Plan Perspect. 1998;24:4.

41. Townsend JW. Effective family planning service components: global lessons from operations research. In: Seidman M, Horn MC, editors. Operations research: helping family planning programs work better. New York: Wiley-Liss; 1991.

Submit your next manuscript to BioMed Central and we will help you at every step:

- We accept pre-submission inquiries

- Our selector tool helps you to find the most relevant journal

- We provide round the clock customer support

- Convenient online submission

- Thorough peer review

- Inclusion in PubMed and all major indexing services

- Maximum visibility for your research

Submit your manuscript at www.biomedcentral.com/submit

C) Biomed Central 